\title{
Implementation of Model View Controller (MVC): Case Study at Student Dormitory of University of Trunojoyo Madura
}

\author{
Ach. Khozaimi ${ }^{1}$, Firdaus Solihin ${ }^{2}$, Aeri Rachmad ${ }^{3}$, Ika Oktaviani Suzanti ${ }^{4}$, Husni $^{5}$, Yoga \\ Dwitya Pramudita $^{6}$, Inayatul Fadilah ${ }^{7}$ \\ $\left\{\right.$ khozaimi@trunojoyo.ac.id ${ }^{1}$, fsolihin@gmail.com $\left.{ }^{2}\right\}$ \\ Faculty of Engineering, University of Trunojoyo Madura. Jl. Raya Telang P.O. \\ BOX 2 Kamal, Bangkalan-Madura, Indonesia $69162^{1234567}$
}

\begin{abstract}
The monitoring process of existing activities in the dormitory is still manual. From the manual process when managers request activity data that has been implemented in the dormitory, then musahhil have to find data so it takes a long time, it's need an application. The application to be used is to apply the concept of MVC (Model, View Controller) using Codeigniter Framework. MVC is a concept whereby to develop a website application that separates the presentation logic with the appearance set by the controller. It is expected that with the monitoring application of dormitory activities with the concept of MVC. All dormitory activities can be monitored properly and easily based on the results of questionnaires from user.
\end{abstract}

Keywords: monitoring, student dormitory, codeigniter MVC framework (model, view, controller).

\section{Introduction}

Monitoring is an activity undertaken by the leadership to see, monitor the organization during the activities and assess the achievement of goals, see the supporting factors and inhibit the implementation of the program [1]. Monitoring of dormitory activities is important to undertake to facilitate managers, administrators and residents in the course of all activities of boarding well. Monitoring done by Musahhil dan Musahhilah. Musahhil is male liaison officer, and Musahhilah is female liaison officer.

Student Dormitory is a place of character education for UTM students and university students (Trunojoyo Madura University). Dormitory Students are managed under the auspices of the managers, musahhil, and musahhilah. There are 5 buildings in the dormitory which are 3 female dormitory buildings (Princess P building, Princess P building, Princess P building) while 2 buildings for male dormitory (Putera D Building, Putera E Building). Dormitory there are 4 floors with facilities that have been provided by the managers and there are some process activities are done manually.

By looking at some of the problems that have been described above the dorms need to be made an application monitoring the activities of the dormitory. In the making of monitoring application of this dormitory, activity will apply the concept of MVC. MVC (Model, View, Controller) is a fairly popular concept in building a web application. Beginning with Small

ICCSET 2018, October 25-26, Kudus, Indonesia

Copyright (C) 2018 EAI

DOI 10.4108/eai.24-10-2018.2280570 
Talk programming language. MVC separates application development based on major components that build an application such as data manipulation, user interface, and the part that the application controls. By using the Model Concept, View, Controller (MVC) this causes the web page to contain little code because the MVC concept of display structure and logic is more structured and easy to develop and work can be done in focus. In a framework, there is usually a good application structure available. Standard coding (1), best practice (2), Design pattern (3), and common function (4). By using the framework developers can focus more on the business process encountered without having to think much of the problem of application structure standard coding and others [2].

With an application of monitoring of dormitory activities with the implementation of MVC concept (Model, View, and Controller) is expected to facilitate the managers and musahhil dormitory in monitoring the process of dormitory activities so that it can be monitored all activities well.

\section{Study Literature}

\subsection{MVC (Model View Controller)}

MVC (Model View Controller) is a fairly popular concept in web application development. Beginning with Small Talk programming language, using the concept (Model, View Controller) MVC will cause the web page contains a little code because the concept of MVC display structure and logic has been separated to allow web work more structured and easy to develop and workmanship can do in focus.

Benefits of using MVC (Model View Controller) i.e. maintenance and changes to program code will be more detailed if one component is developed or changed then other components cannot change. Example if there is a change in view that is in the code view file then the code file model and the controller cannot change. [3]

There are 3 types of components that build an MVC (Model View Controller) pattern in an application.

1. User Interaction

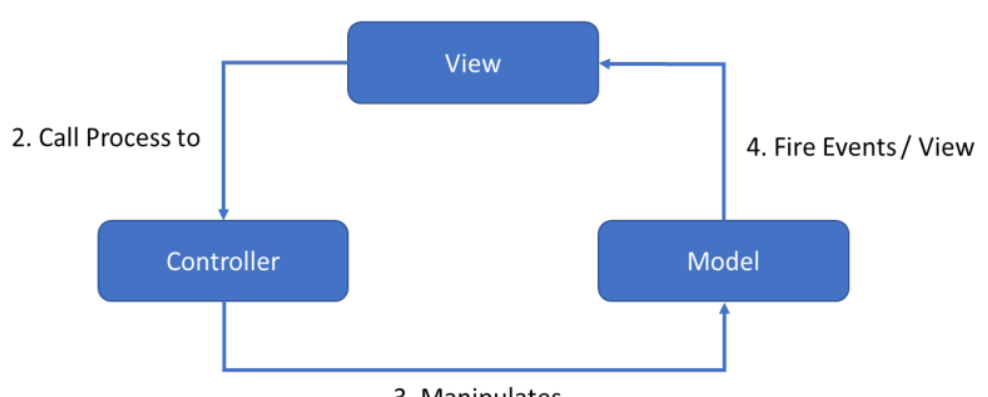

Fig. 1. Architecture MVC Component. 
a. Model: is the data structure. Physically the model class will contain code functions that will assist in any database-related process such as inserting, editing, obtaining and deleting a database.

b. The View is information delivered to the user that contains the full details of the user interface implementation by involving graphical components that provide the representation of the application's internal processes and guide the flow of user interaction with the application.

c. The controller is an intermediate between the model and the view and all the resources needed to process HTTP requests. Responsible for the event shelter created by the user from the view and update the component model using data from the user [4].

User interaction with the program is drawn with the direction of the big arrow towards the view. Then view call controller. The controller will then create or manipulate the model. This model will be given to the view to be displayed to the user. Thus the view task is to handle the appearance of the program and the interaction between the user and the program. The controller coordinates between the view and the model, while the model is the part that works behind the screen to satisfy user requests in an interaction. The purpose of dividing the program into these three major sections is to separate the focus of attention, responsibility, and logic into their respective sections. View only focuses on the view and handles interaction with the user. The model focuses only on the manipulation of non-visual and logic objects in it to satisfy the scenario of a business process, whereas the controller receives input from the view, creates and manipulates the model, then assigns a model.

\subsection{Framework}

The framework is a framework, a framework can also be interpreted as a collection of scripts (especially classes and functions that can help developers or programmers in handling various problems in programming such as connection to the database, calling the variables and files that will be used in making the application website [5]. Some advantages of using the framework include:

a. The time of making our website application is much shorter

b. Website application code becomes easier to read because it is small and its principal. The details are the code of the framework and this may not be thought of, guaranteed

c. Our website becomes easier to fix because we do not need to focus on all components of the website code, especially the system framework code [6].

\subsection{CodeIgniter}

CodeIgniter (CI ) is a framework that is used to create a web-based application that is compiled using the PHP language. In CI there are several classes that form Library and helper. Both functions to help programmers in developing the application. [3]

\subsection{The concept of monitoring}

On other occasions monitoring is also defined as a step to assess whether the activities carried out are in accordance with the plan, identifying problems that arise to be directly addressed. 
Conducting an assessment of whether the work patterns and management used are appropriate to achieve the objectives, knowing the link between the activities with the aim to obtain a measure of progress (Subtari 2012). In other words, Monitoring is one process in the organization's very important activities that can determine the implementation or not an organization's objectives. The purpose of monitoring is to ensure that the main task of the organization can be run in accordance with the predetermined plan (Avina 2012) [7].

\section{Methodology}

In this study used Waterfall Model in building applications, this method is a system development method that each stage of development is done in sequence. In each sequence of this method, there are several things done that are like in the picture below.

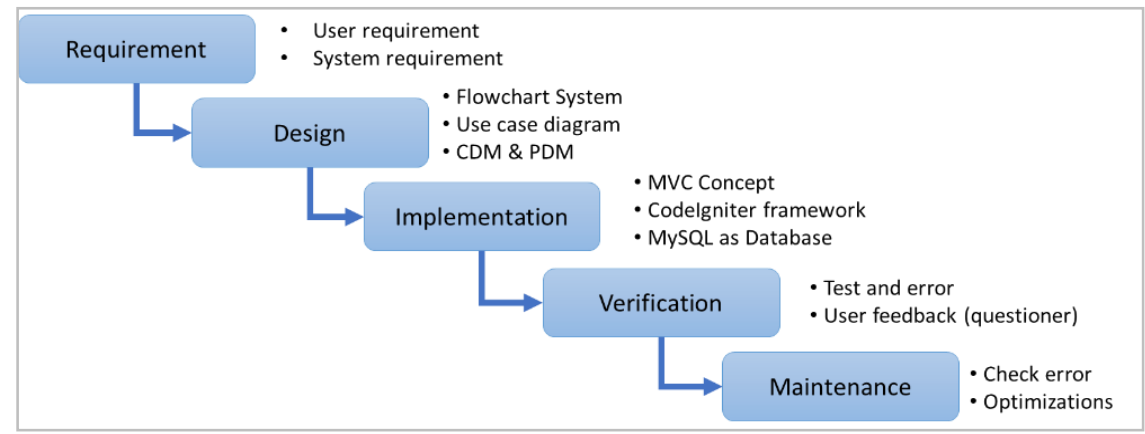

Fig. 2. Waterfall model.

\section{Design}

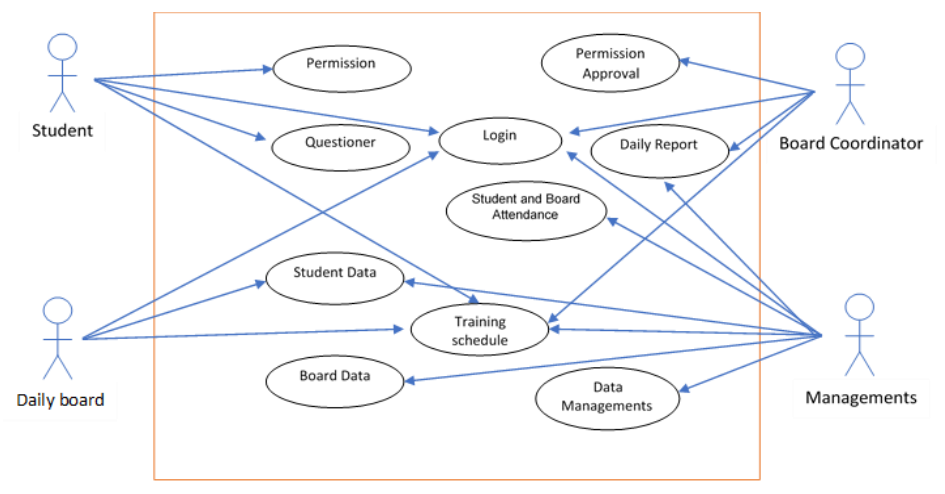

Fig. 3. Use case diagram. 
Figure 3 Is a description of the system in the form of use case diagram described in outline. Consists of 4 Users / Actor including Student, Daily board, Board coordinator, management which each has its own level and features the built system.

\section{$5 \quad$ Result and Testing}

\subsection{Result}

The purpose of this research is to build a monitoring application that able to handle permission process, dormitory activity and to know how efficient concept View Controller Model able to facilitate developer in application development.

Here is a view of an application that has been made:

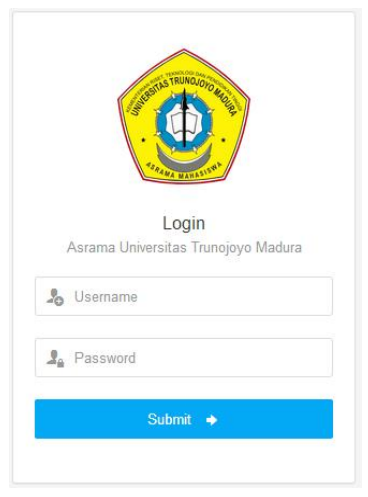

Fig. 4. Login Page.

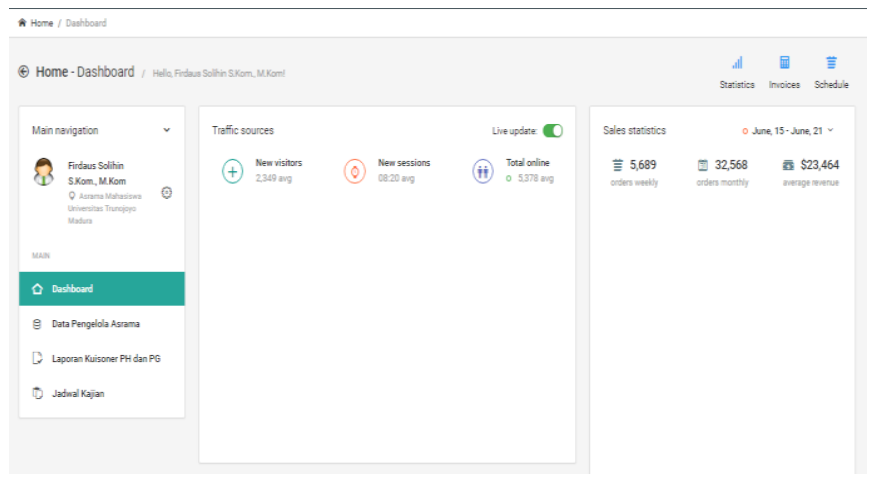

Fig. 5. Dashboard Manager.

On the login page, there are two forms namely username and password where for the username is inputted based on NIM. While on this manager user page there is a menu that is manager data, report of PH questionnaire (Daily management) and PG (Building Management) and menu schedule of study.

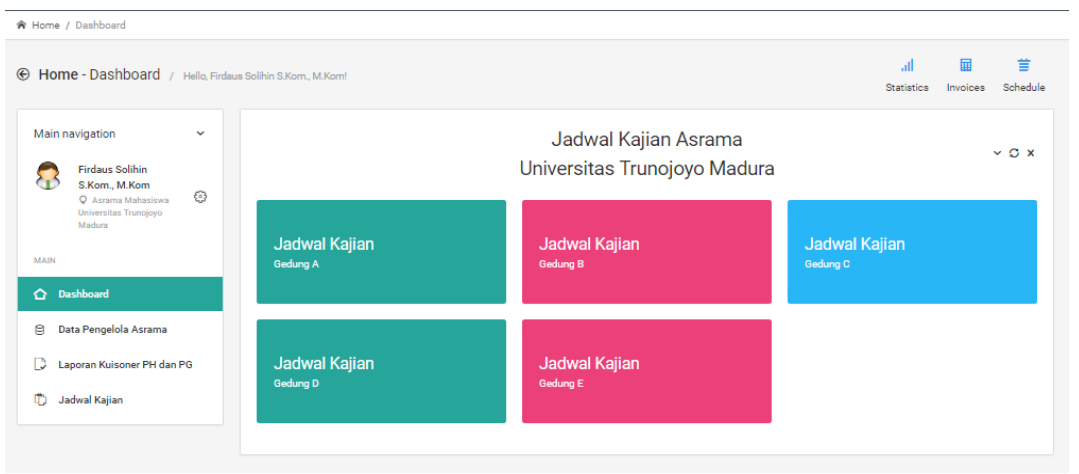

Fig. 6. Dormitory Schedule page. 
Figure 6 , there is a menu that is the schedule of the study of building A, building B, Building C, Building D and Building E, where from each schedule of the study is different. User manager can input study schedule of each building.

Figure 7, citizens can make late residents permissions when the residence residents are back or home past the hostel hours.

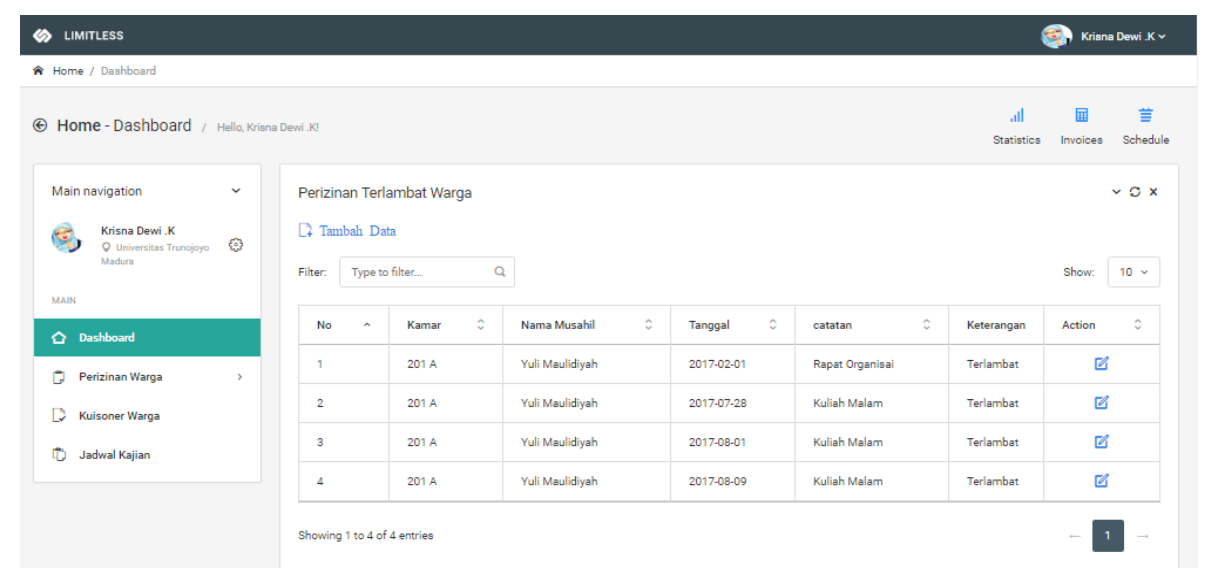

Fig. 7. Late Citizens Licensing page.

\subsection{Testing}

Testing the application is done by presenting the application that has been made, then followed by filling questionnaire related to the conformity of features and appraisal on the application that has been made to each related party, including Students (as Prospective Citizens), Citizen, Musahhil, Building Coordinator, Daily Management and Hostel Manager.

Next will be analyzed by calculating the percentage of answers on each type of respondent. The data obtained can be calculated using the following formula:

$$
\mathrm{P}=\frac{F}{N} \times 100 \%
$$

where:

$$
\begin{aligned}
& \mathrm{P}=\text { percentage of respondents' answers } \\
& \mathrm{F}=\text { number of respondents' answers } \\
& \mathrm{N}=\text { number of respondents }
\end{aligned}
$$

Based on the calculation of questionnaire about monitoring application of dormitory activity by using MVC concept (Model View Controller) which has been done on all user $100 \%$, it can be concluded that Application entered in a good category as a whole and feasible to be implemented in the dorm. 


\section{Conclusion}

The concept of MVC (Model View Controller) can facilitate developers and be able to create an application without affecting other processes, this can be proven when making changes to the Model and View files. Based on the calculation of questionnaire about monitoring application of dormitory activity by using MVC concept (Model View Controller) which has been done, it can be concluded that the average of application percentage is $100 \%$ accordingly.

\section{References}

[1] T. syamsiyah R, Application of lecturing monitoring and evaluation. 2016.

[2] Aguide and best practice. 2017.

[3] S. M. dan tekad matulatan M. I. T. Fanny fardany, Eka Suswaini, Occupational Monitoring Application of HSE Department (Health Safety Environment) with MVC Method. 2016.

[4] M. I. Tanjung, Analysis and Design of Website Based Information System Using MVC Architecture with Framework CodeIgniter. 2011.

[5] D. Rosmala, MVC framework compilation (CodeIgniter and PHP cake) in web-based applications. 2012.

[6] Become a master of PHP with CodeIgniter Framework. 2016.

[7] A. Herlina, "Information System Monitoring software development at the stage of web-based Development," J. Inform., vol. III, 2016. 